\title{
Influence of long (16L:8D) and short (8L:16D) photoperiods on blood metabolites and hepatic metabolism in Olive flounder, Paralichthys olivaceus
}

\author{
Huafeng Zou ${ }^{1,2}$, Xianshou Bai ${ }^{2}$, Yuhong Feng ${ }^{2}$, Ying Zhang ${ }^{2}$, Youji Wang ${ }^{1,2}$ and Weiqun Lu L $^{1,2^{*}}$
}

\begin{abstract}
In the present study the influence of long photoperiod (LP, 16L:8D) and short photoperiod (SP, 8L:16D) on hepatic energy metabolism in the olive flounder (Paralichthys olivaceus) was investigated. Flounders were maintained under LP or SP conditions for 2 weeks then plasmatic and hepatic parameters were assessed. At the plasmatic level, the concentration of cortisol was enhanced in flounder maintained under LP compared to SP. Alkaline phosphatase (ALP), alanine aminotransferase (ALT) and aspartate aminotransferase (AST) enzyme activities in plasma also increased in LP flounder. There was no significant difference in plasma glucose levels between the two experimental groups. Plasma osmotic pressure, $\mathrm{Na}$ and $\mathrm{Cl}$ levels were significantly higher in LP compared to the SP group. In liver, a significant decrease of triglycerides together with an increase in glycogen was observed in the LP group. Hepatic hs/ and pepck and muscle hs/ mRNA expression in LP was significantly higher in the SP group. Overall the results indicate that the LP treatment caused a mild stress response and increased hepatic energy metabolism in the flounder, which in turn could affect osmoregulation. In conclusion, it would appear that LP treatment can adversely influence hepatic energy metabolism in adult olive flounder under fasting condition.
\end{abstract}

Keywords: Photoperiod, Olive flounder, Hepatic parameters, Energy metabolism, hsl, pepck

\section{Background}

The influence of photoperiod on fish has been studied in respect to its effects on growth, reproduction and migration (Boeuf et al. 1999). Photoperiod has been considered as one of the most important growth promoting factors in several fish species, it affects not only feeding behavior but also physiological condition. The use of different light regimes is common in commercial aquaculture (Barimani et al. 2013; Sonmez et al. 2009; Taylor et al. 2005). A large number of literature has been reported a relationship between photoperiod and growth of fish, but the findings are often species specific. In some species, including

\footnotetext{
${ }^{*}$ Correspondence: wqlv@shou.edu.cn

${ }^{1}$ Key Laboratory of Exploration and Utilization of Aquatic Genetic Resources, Ministry of Education, Shanghai Ocean University, Shanghai 201306, China

Full list of author information is available at the end of the article
}

barramundi Lates calcarifer (Barlow et al. 1995) and gilthead sea bream Sparus aurata (Tandler and Helps 1985), extending day length increases larval growth and survival; however, long photoperiod regimes result in physical stress and adverse growth effects in rainbow trout (Oncorhynchus mykiss) (Leonardi and Klempau 2003).

Olive flounder (Paralichthys olivaceus) is an economically important fish distributed in coastal China, Japan and South Korea (Dou et al. 2003; Xu et al. 2012). The increasing demand for flounde makes it an important candidate for commercial aquaculture. Different light regimes have been used to regulate the growth and survival of larval flounder (Dou et al. 2003; Moustakas et al. 2004), but the effect of photoperiod on metabolism in adult flounder is unstudied.

The flounder can adjust its physiology and metabolism to modifications in photoperiod and food availability, and these adjustments may occur in anticipation 
of the change, allowing flounders to keep homeostatic responses needed for survival in different conditions ( $\mathrm{Lu}$ et al. 2007). The liver is an essential metabolic organ for growth in fish, it stores lipid and glycogen when energy and food are in sufficient supply and degrades and releases them into the blood during fasting (Barcellos et al. 2010). Phosphoenolpyruvate carboxykinase (pepck) and hormone-sensitive lipase $(h s l)$ catalyze glycogen and lipid metabolism, respectively and contribute to maintain energy homeostasis during food deprivation. In the wild flounder face periods of starvation during overwintering, spawning and migration. In aquaculture practice, flounders are also exposed to short-term food deprivation during sorting, transportation and when they are temporarily maintained in holding tanks. What is more, artificial photoperiod manipulation may also alter physiologic metabolism and affect survival of flounders.

Therefore, to understand the possible involvement of photoperiod on metabolic effects in flounder, we conducted an experiment by exposing adult olive flounder to a long (16L:8D, LP) and short (8L:16D, SP) photoperiod. First we compared the concentration of cortisol, alkaline phosphatase (ALP), alanine aminotransferase (ALT) and aspartate aminotransferase (AST) in the plasma. Then we analyzed the glucose, glycogen and triglyceride levels in plasma and liver tissue and finally we investigated transcripts associated with lipolysis and glycogen metabolism, hepatic pepck and hsl mRNA expression, respectively. The aim of this study was to investigate the influence of long photoperiod manipulation on energy metabolism and the general physiology of olive flounder.

\section{Methods}

\section{Ethics statement}

All animal procedures were approved by the Animal Ethics Committee of Shanghai Ocean University (Shanghai, China) and complied with the Guidelines on Ethical Treatment of Experimental Animals set by the Ministry of Science and Technology, China.

\section{Animal}

Gynogenetic olive flounder were produced as previously described (Liu et al. 2012) and were reared until they were approximately one-year-old at the Central Experimental Station of Chinese Academy of Fisheries Sciences (Beidaihe, Hebei, China). The experiment was conducted at the same location on September 15-30, 2012. A total of 18 gynogenetic olive flounder (body weights: $600 \pm 50 \mathrm{~g}$ ) were randomly distributed between 18 tanks in a flow-through, filtered seawater circuit at $20 \pm 1{ }^{\circ} \mathrm{C}$. Black plastic light-proof curtains surrounded each set of tanks and artificial illumination was provided with white fluorescent lamps. Mean light intensity was approximate
40 lux near the bottom in the centre of the seawater tanks. Fish were starved throughout the experiment.

\section{Animal experiments}

Fish were acclimated under short photoperiod (8L:16D, SP; $\mathrm{n}=6$ ), middle photoperiod (12L:12D, MP; $\mathrm{n}=6$ ) and long photoperiod (16L:8D, LP; $\mathrm{n}=6$ ) for 2 weeks and then removed from each photoperiod tank without anaesthetic. All fish were stunned by percussion and humanely killed. Blood was collected within $90 \mathrm{~s}$ of death through the caudal blood vessels. Blood samples were aliquoted into ammonium-heparinized tubes and plasma was obtained by centrifugation for $5 \mathrm{~min}$ at 13,000g. Liver and muscle tissues were removed and snap frozen in liquid nitrogen for subsequent RNA extraction or biochemical measurement.

\section{Cortisol measurement}

The level of cortisol in plasma was measured using a commercial RIA kit purchased from Beijing North Institute of Biotechnology (Beijing, China). The detection limit for cortisol was $2 \mathrm{ng} / \mathrm{mL}$ and the intra- and interassay coefficients of variation were 10 and $15 \%$, respectively. Samples were analyzed in triplicate within one assay to avoid inter-assay variations.

\section{Analysis of plasma osmolality and ions concentration}

Osmolality was measured using a vapor pressure microosmometer (Vapro 5520 Wescor, Logan, USA), sodium concentrations were determined by atomic absorption spectrophotometry (Thermo Elemental Solaar S4, Winsford Cheshire, UK), chloride concentrations were analyzed by electrode titration (Corning Chloride Analyzer 925, Corning, NY).

\section{Measurement of plasma and liver metabolites}

Glucose, glycogen and triglyceride levels in plasma and liver of fish were measured using commercial kits from Nanjing Jiancheng Bioengineering Institute (Nanjing, China) according to the manufacturer's manuals. Methods were adapted with 96-well plates and values were determined spectrophotometrically using a microplate reader (Synergy, BioTek, Winooski, VT). Enzyme activities of ALP (AMP buffer method), ALT (IFCC method) and AST (IFCC method) in plasma were measured on an automated BS200 chemistry analyser (Mindray, Shenzhen, China).

\section{Gene expression analysis by real-time PCR}

Total RNA was extracted from tissues using Trizol reagent (Invitrogen, Carlsbad, CA, USA) and treated with RQ1DNAse (Promega, Madison, WI, USA) to remove DNA contamination. The concentration of RNA was measured 
using a NanoDrop ND-2000 Spectrophotometer (Wilmington, DE, USA). RNA integrity was confirmed by denaturing agarose gel electrophoresis. Total RNA $(1 \mu \mathrm{g})$ was reverse transcribed into cDNA using Superscript II reverse transcriptase (Takara). Gene expression levels were determined by real-time quantitative RT-PCR using an ABI 7500 Real-Time PCR system (Applied Biosystems, Foster City, CA). Relative quantification of the target gene transcripts was done using $\beta$-actin gene expression as the reference gene. Specific primers for $h s l$, pepck and $\beta$-actin transcripts were designed using flounder mRNA sequences for hsl (AB828672), $\beta$-actin (AF135499) and pepck using Primer Premier 5.0 software. The sequence of the olive founder pepck gene was obtained from GEO database GSE47556 (Kondo et al. 2014). Primers were commercially synthesized (Sangon Biotech, Shanghai, China) (Table 1), and validation of primers for qRT-PCR were performed using standard ABI protocols. Thermal cycling was initiated by incubation at $95{ }^{\circ} \mathrm{C}$ for $5 \mathrm{~min}$ using hot-start Taq DNA polymerase; $40 \mathrm{PCR}$ cycles were performed, and consisted of heating at $95^{\circ} \mathrm{C}$ for $15 \mathrm{~s}$, followed by $60{ }^{\circ} \mathrm{C}$ for $30 \mathrm{~s}$ and $72{ }^{\circ} \mathrm{C}$ for $30 \mathrm{~s}$. Following the final PCR cycle, melting curves were systematically monitored to ensure that only one fragment was amplified.

\section{Statistical analysis}

The $2^{-\Delta \Delta}$ Ct method was used to analyze the real-time PCR data (Livak and Schmittgen 2001), and amplified transcripts were expressed as the fold change relative to the mean value of the SP group. All data were presented as the mean \pm SEM and statistical differences were detected using an unpaired Student's $t$ test using SPSS software version 18.0 (SPSS Inc., Chicago, IL). The cut-off for significance was $\mathrm{p}<0.05$.

\section{Results}

Mass and the concentration of cortisol in flounder

No mortality or disease was observed in either group of fish during the experiment. The mass of flounders at the end of the experiment was significantly lower $(p<0.05)$

\begin{tabular}{lll}
$\begin{array}{l}\text { Table } \mathbf{1} \text { Primer } \\
\text { amplifications }\end{array}$ & pair sequences used for & real-time PCR \\
\hline RT-PCR primer & $\mathbf{5}^{\prime}-\mathbf{3}^{\prime}$ & $\begin{array}{l}\text { Annealing tem- } \\
\text { perature }\left({ }^{\circ} \mathbf{C}\right)\end{array}$ \\
\hline HSLF & ACAGCAGTCACGGTTTGGT & 60 \\
HSL R & AGAGGAAGGCGTAGAGGGA & \\
PEPCKF & GAACGGCTTCTTCGGTG & 60 \\
PEPCKR & AAGCGGGAGTTGGGTG & \\
$\beta$-actin F & GGAAATCGTGCGTGACATTAAG & 60 \\
$\beta$-actin R & CCTCTGGACAACGGAACCTCT & \\
\hline
\end{tabular}

HSL hormone-sensitive lipase; PEPCK phosphoenolpyruvate carboxykinase than the initial body weight, and no significant difference in mass occurred between two groups (data not shown).

Plasma cortisol levels in flounder acclimated to SP, MP and LP are shown in Fig. 1A. Photoperiod significantly affected stress indicators in flounder and cortisol was significantly increased in LP $(9.07 \pm 0.41 \mathrm{ng} / \mathrm{mL})$ compared with SP $(5.96 \pm 0.64 \mathrm{ng} / \mathrm{mL})$ and $\mathrm{MP}(8.06 \pm 0.55 \mathrm{ng} / \mathrm{mL})$ flounder $(\mathrm{P}<0.01)$.

\section{ALP, ALT and ASP activity in plasma of flounders}

Three serum biochemical parameters, ALP, ALT and ASP, that are associated with liver damage were analyzed (Fig. 1B). LP treatment significantly increased the activity of ALP ( $2.98 \pm 0.48$ vs. $5.02 \pm 0.58$ unit $/ \mathrm{L}, \mathrm{P}<0.05)$, AST (12.08 \pm 0.69 vs. $12.48 \pm 0.55$ unit/L, $\mathrm{P}<0.01)$ and ALT $(36.56 \pm 3.34$ vs. $53.76 \pm 5.68$ unit/L, $\mathrm{P}<0.05)$ relative to the SP group. The data of ALT $(4.18 \pm 0.29$ unit/L) and AST $(42.73 \pm 2.86$ unit/L) in MP showed no difference compare to SP and LP, while ALP (14.02 \pm 0.56 unit/L) showed significant increase than SP group.

\section{Osmolality and ion concentration in plasma of flounders}

The concentration of $\mathrm{Na}^{+}$and $\mathrm{Cl}^{-}$in plasma is shown in Fig. 2. LP caused a significant increase in plasma $\mathrm{Na}^{+}$and $\mathrm{Cl}^{-}(\mathrm{P}<0.05)$ relative to the SP and MP group (Fig. 2A, B). Elevated level of plasma osmolality $(\mathrm{P}<0.05)$ was observed in LP compared with SP and MP flounder (Fig. 2C).

\section{Glucose, glycogen and triglycride in blood and liver tissue} From the results of detected above, significant differences were mainly observed in LP and SP group, and the data of MP were in intermediate range between SP and LP group, so next analysis was focused on LP and SP group. Plasma and liver metabolites in flounder acclimated to modified photoperiod are shown in Fig. 3. The concentration of triglyceride in plasma was significantly higher $(\mathrm{p}<0.05)$ in the LP group relative to the SP group (Fig. 3a). In contrast, triglycerides in the liver of the LP group was significantly lower $(\mathrm{p}<0.05)$ than the SP group (Fig. 3b) and glycogen in the liver showed a reverse trend (Fig. 3c). There was no significant difference in plasma glucose between SP and LP groups (Fig. 3d).

\section{mRNA expression of $h s /$ and pepck in the liver and muscle of flounder}

Expressions of $h s l$ and pepck mRNA in the liver are presented in Fig. 4. Both hsl (Fig. 4a) and pepck mRNA (Fig. 4b) expression in the liver of the LP group was significantly higher than those in SP group $(\mathrm{P}<0.05)$. Expression of $h s l$ mRNA in the muscle of the LP group was also significantly higher $(\mathrm{P}<0.05)$ than that in SP group (Fig. 4c). 

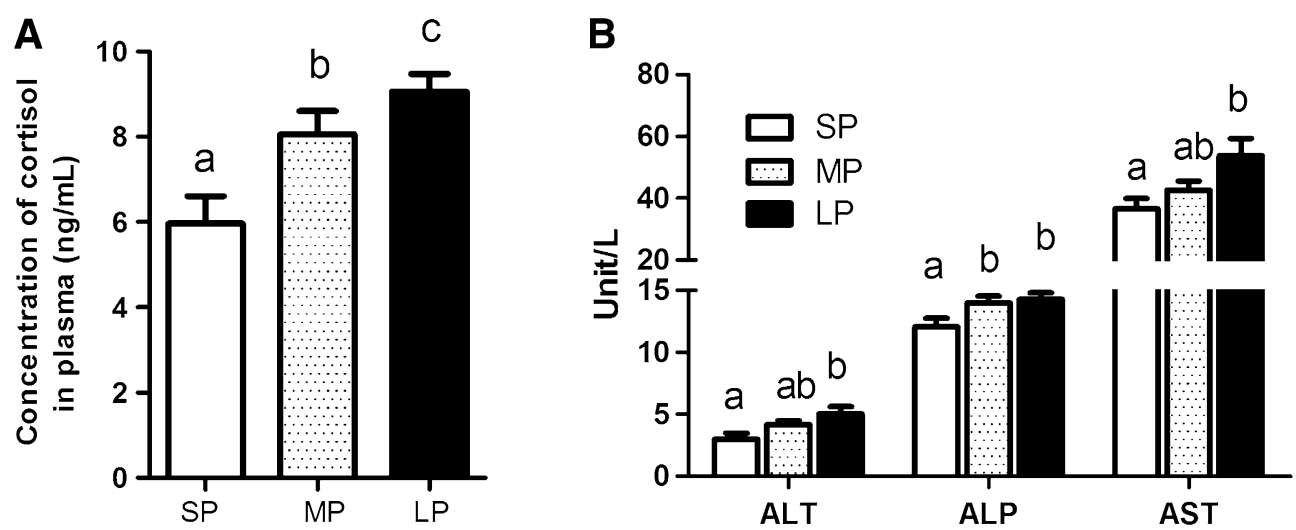

Fig. 1 The concentration of cortisol (A) and three different biochemical parameters (B) alkaline phosphatase (ALP), alanine aminotransferase (ALT) and aspartate aminotransferase (AST) in plasma of flounders. Data are presented as mean $\pm \mathrm{SEM}, \mathrm{N}=6$. Different letters above bars mean significant differences among the three groups
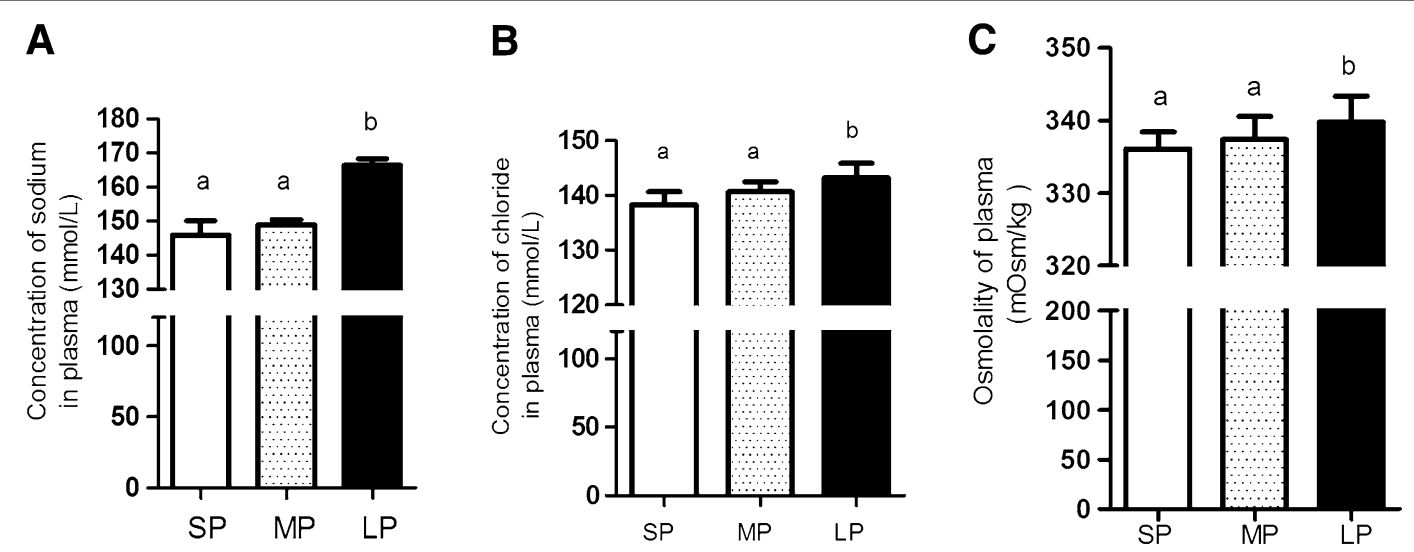

Fig. 2 Ion parameters in plasma in two groups of flounders. The concentration of sodium $(\mathbf{A})$, chloride $(\mathbf{B})$ and osmolality of plasma $(\mathbf{C})$. Data are presented as mean $\pm \mathrm{SEM}, \mathrm{N}=6$. Different letters above bars mean significant differences among the three groups

\section{Discussion}

The artificial extended photoperiod treatment for flounders presents physiological challenges with respect to osmoregulation and hepatic metabolism when food are not available in this study. These physiological challenges are revealed by the stress response detected in flounder exposed to a LP. In this study we observed that LP manipulation resulted in a mild stress response in flounder. The level of plasma cortisol was $9.07 \pm 0.41 \mathrm{ng} / \mathrm{mL}$ in LP, which is lower than the $25 \pm 4.4 \mathrm{ng} / \mathrm{mL}$ previously reported in flounders exposed to transportation stress (Hur et al. 2007). The lower levels of cortisol detected in the present study suggests that LP is a milder stressor than transportation. The significant increase in plasma cortisol in flounder exposed to LP agrees with the results of a study with African sharptooth catfish Clarias gariepinus, exposed to a long photoperiod (6D:18L) relative to those reared under shorter periods of light (24D:00L and 18D:06L) (Almazán-Rueda et al. 2005).

AST and ALT are aminotransferases present in the liver and spleen. Their plasma levels are low when animals are healthy, but increase when animals are stressed or when tissue necrosis occurs (Wells et al. 1986; Jung et al. 2003). ALT and AST leak into the circulation when liver cells are damaged and high levels of these enzymes in the blood are an indicator of liver damage. In this study we observed increased level of enzymes (AST, ALT, ALP), suggesting LP may exert adverse effect on liver metabolism in flounder. The results of the present study are similar to previous studies in which flounder were stressed by food deprivation or metal pollution (Park et al. 2012; Oner et al. 2008).

For seawater acclimation fish, gills absorb water and excrete sodium and chloride to maintain osmotic balance of blood; a highly energy-consuming process (Bœuf 

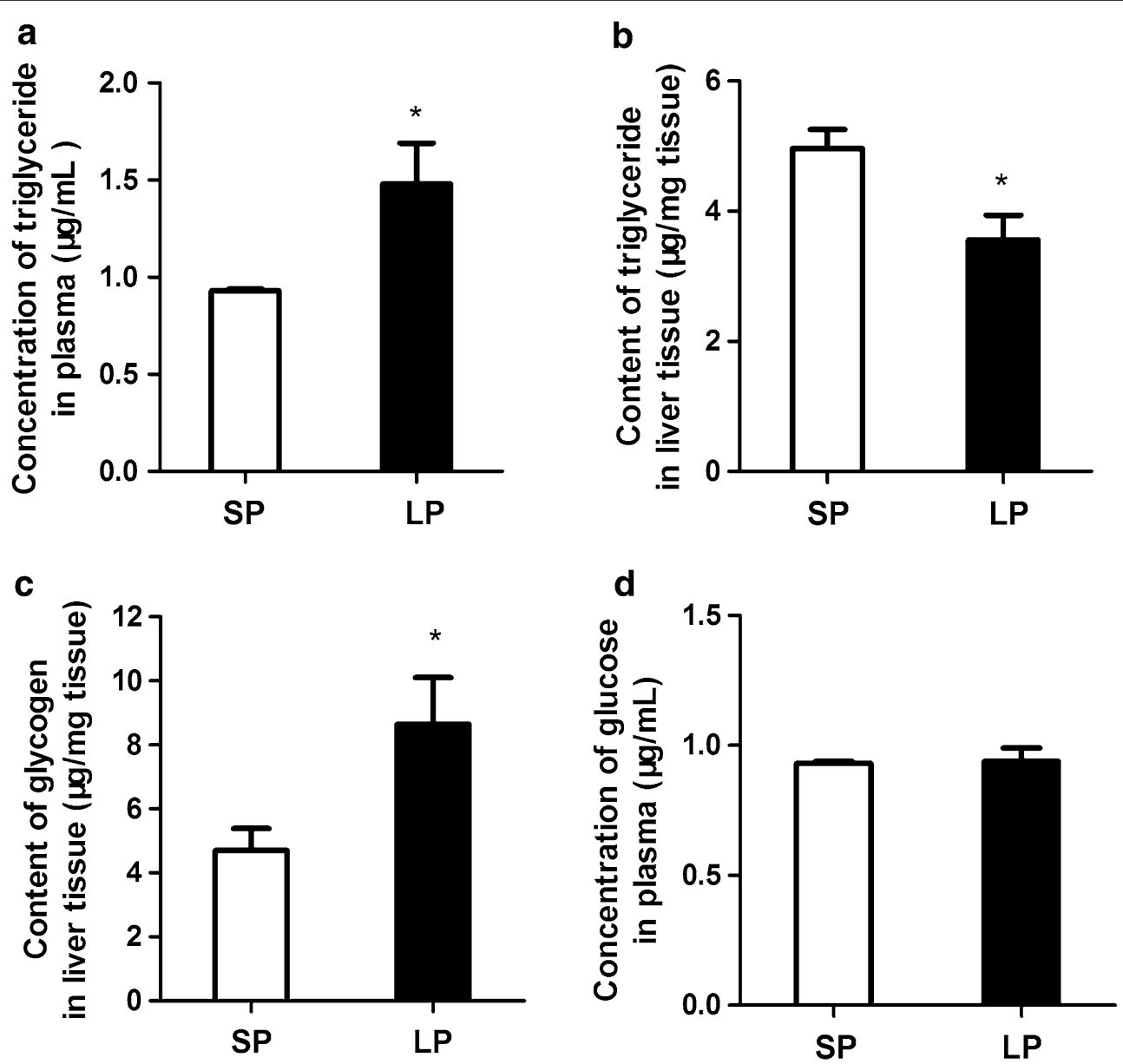

Fig. 3 The blood and liver metabolic parameters in two groups of flounders. Content of triglyceride in plasma (a) and liver tissue (b), content of glycogen in liver tissue $(\mathbf{c})$, concentration of glucose in blood $(\mathbf{d})$. Data are presented as mean $\pm \mathrm{SEM}, \mathrm{N}=6$. Asterisk $\mathrm{P}<0.05$ indicates significant difference between the two groups
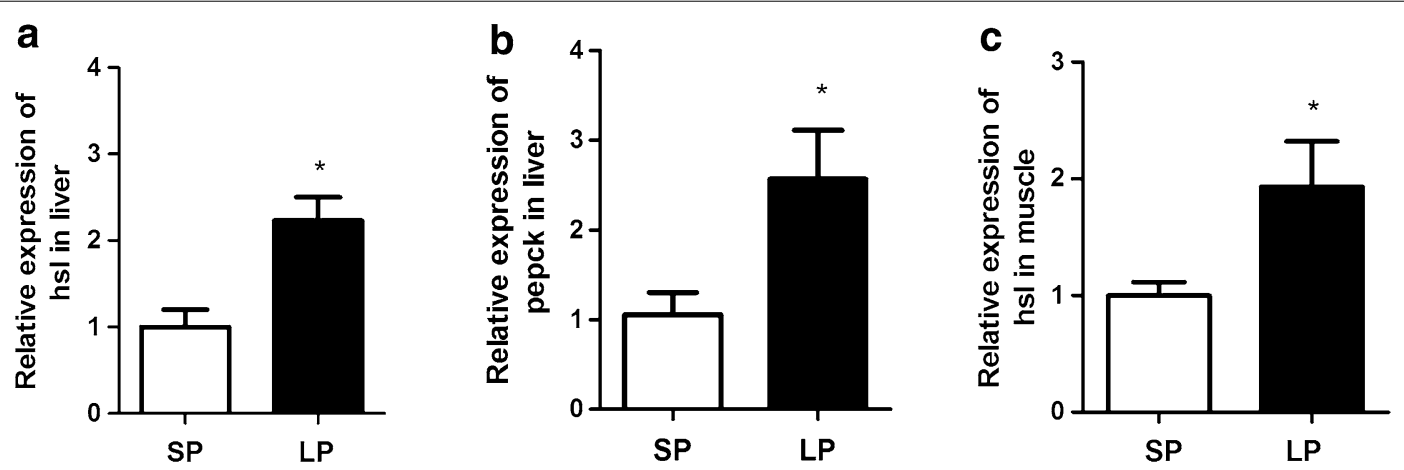

Fig. 4 Relative expression level of hormone-sensitive lipase hsl (a) and Phosphoenolpyruvate carboxykinase pepck (b) gene expression in liver, and hsl expression in muscle $(\mathbf{c})$. Relative expression data was calculated by the method $2-\Delta \Delta C \mathrm{Ct}$, Data are presented as mean $\pm \mathrm{SEM}, \mathrm{N}=6$. Asterisk $\mathrm{P}<0.05$ indicates significant difference between the two groups

and Payan 2001; Iwama et al. 1997). Plasma osmolality is a useful marker to determine the effectiveness of osmoregulatory regulation. One of the main energy costs of osmoregulation is ion pumping (Urbina and Glover. 2015). Therefore, the energy state will affect the function of the gill and the concentration of ions in fish plasma. In 
the current study the higher $\mathrm{Na}, \mathrm{Cl}$ level and osmolality in plasma of the LP group maybe revealed low energy availability resulting both from food deprivation and photoperiod manipulation. The results of the present study were consistent with the significantly higher levels of plasma $\mathrm{Na}$ and $\mathrm{Cl}$ in tilapia (Oreochromis niloticus) that were fooddeprived (Vijayan et al. 1996). Increased plasma $\mathrm{Na}$ and $\mathrm{Cl}$ were also reported in striped jack (Pseudocaranx dentex) exposed to a long photoperiod (16D, 8L) when compared to a short photoperiod (8L, 16D) (Pavlidis et al. 1999).

Liver is the main organ involved in glycogen/glucose turnover in fish, and during fasting its metabolism is enhanced so that glucose can be made available for other metabolic and osmoregulatory process (Blasco et al. 2001; Klee et al. 1990). In the present study the level of glucose in blood showed no difference between the LP and SP groups and a similar observation was made in the silver catfish (Rhamdia quelen) fasted for 14 days $\mathrm{d}$ (Barcellos et al. 2010). Glyconeogenesis process means to produce glucose from non-carbohydrate substrates (Klover and Mooney 2004). Pepck catalyzes the rate-limiting step in hepatic glyconeogenesis. Glycogen metabolism in liver tissue is the principal energy source in both vertebrates and invertebrates, especially during environmental fluctuation such as food deprivation (Kullgren et al. 2010; Mariano et al. 2009). In this study, the glycogen content of the liver was significantly higher in the LP group relative to the SP group, implying that the former group have a higher glyconeogenesis capacity. Increased cortisol concentration combined with higher level of hepatic pepck gene expression and glyconeogenesis is consistent with the result of Vijayan et al. (1994), who reported that cortisol treatment increases glyconeogenesis in rainbow trout (Oncorhynchus mykiss) hepatocytes. The results of the present study support the notion that cortisol-induced glyconeogenesis is important for the maintenance of glucose levels during energy demand in flounders (Vijayan et al. 2003).

Lipolysis of triglyceride stored in the liver results in the liberation of glycerol and nonesterified fatty acids that are released into the blood for use by other organs (Reshef et al. 2003). During time of energy deprivation in fasting, the LP group of flounders have higher e energy requirement than SP group, and when food is unavailable this need is met by increased hepatic lipolysis. The triglyceride content of the liver in the LP group was significantly lower than the SP group, while the content of triglycerides in blood showed reversed tendency. $\mathrm{H} s l$, the rate-limiting enzyme for lipolysis, participates in the hydrolysis of triacylglycerol to generate fatty acids and glycerol for use as an energy substrate by other organs (Mulder et al. 1999).
The amount of triglyceride in liver of the LP group was significantly lower than that of SP group, and this with the higher level of $h s l$ mRNA expression in liver and muscle supports the idea that LP flounder have enhanced lipid degradation to meet their increased energy demand. This result is in line with the study of Tian (2013), who reported increased $h s l$ mRNA levels in the liver of Nile tilapia (Oreochromis niloticus) during fasting.

Studies in mammal with liver-specific pepck knock-out mice found a dramatic increase in hepatic triglycerides in the liver of pepck null mice (Burgess et al. 2004), suggesting that glycogenesis involving PEPCK is linked with lipolysis in liver tissue. In our study we observed significantly higher pepck mRNA and enhanced glycogen associated with decreased triglyceride in liver of LP flounder, which suggests that utilization of triglyceride reserves in the liver was significantly higher in sthe LP flounders relative to the SP flounder.

In conclusion, our results suggest that long photoperiod manipulation result in mild stress response and increased energy requirement in flounder under conditions of food deprivation, and the shortage of energy affect osmoregulatory function. LP increased lipolysis of triglyceride and glycogenesis in the liver in response to the increased energy requirements. One of the main features of aquaculture is feeding at the maximum possible rate, so our results may not have relevance for normal feeding practices in flounder aquacultures. Nonetheless, since aquaculture practice inevitably involve periods of food deprivation, such as sorting, transportation and holding in temporary tanks, if they are simultaneously exposed to LP it may have a negative effect and should be taken into account during aquaculture of flounder.

\section{Authors' contributions}

Conceived and designed the experiments: WL; Performed the experiments: $H Z$, XB, YF, YZ; Assisted with discussion of results: YW; Wrote the paper: HZ. All authors read and approved the final manuscript.

\section{Author details \\ ${ }^{1}$ Key Laboratory of Exploration and Utilization of Aquatic Genetic Resources, Ministry of Education, Shanghai Ocean University, Shanghai 201306, China. ${ }^{2}$ College of Fisheries and Life Science, Shanghai Ocean University, Shang- hai 201306, China.}

\section{Acknowledgements}

The authors are grateful to the anonymous reviewers for useful comments and suggestions. This work is supported by Grants from the National Natural Science Foundation of China (31572599, 31072228, 41376134), Startup Foundation for Doctors of Shanghai Ocean University (A-0209-13-0105384).

\section{Competing interests}

The authors declare that they have no competing interests.

Received: 21 January 2016 Accepted: 17 June 2016

Published online: 29 June 2016 


\section{References}

Almazán-Rueda P, Van Helmond ATM, Verreth JAJ, Schrama JW (2005) Photoperiod affects growth, behaviour and stress variables in Clarias gariepinus. J Fish Biol 67:1029-1039

Barcellos LJG, Marqueze A, Trapp M, Quevedo RM, Ferreira D (2010) The effects of fasting on cortisol, blood glucose and liver and muscle glycogen in adult jundiá Rhamdia quelen. Aquaculture 300:231-236

Barimani S, Kazemi MB, Hazaei K (2013) Effects of different photoperiod regimes on growth and feed conversion rate of young iranian and french rainbow. World Appl Sci J 21:1440-1449

Barlow CG, Pearce MG, Rodgers L, Clayton P (1995) Effects of photoperiod on growth, survival and feeding periodicity of larval and juvenile barramundi Lates calcarifer (Bloch). Aquaculture 138:159-168

Blasco J, Marimón I, Viaplana I, Fernández-Borrás J (2001) Fate of plasma glucose in tissues of brown trout in vivo: effects of fasting and glucose loading. Fish Phys Biochem 24:247-258

Boeuf G, Le Bail PY (1999) Does light have an influence on fish growth? Aquaculture 177:129-152

Bœuf G, Payan P (2001) How should salinity influence fish growth? Comp Biochem Physiol C Toxicol Pharmacol 130:411-423

Burgess SC, Hausler N, Merritt M, Jeffrey FM, Storey C, Milde A, Koshy S, Lindner J, Magnuson MA, Malloy CR, Sherry AD (2004) Impaired tricarboxylic acid cycle activity in mouse livers lacking cytosolic phosphoenolpyruvate carboxykinase. J Biol Chem 279:48941-48949

Dou S, Masuda R, Tanaka M, Tsukamoto K (2003) Identification of factors affecting the growth and survival of the settling Japanese flounder larvae, Paralichthys olivaceus. Aquaculture 218:309-327

Hur JW, Park IS, Chang YJ (2007) Physiological responses of the olive flounder, Paralichthys olivaceus, to a series stress during the transportation process. Ichthyol Res 54:32-37

Iwama GK, Takemura A, Takano K (1997) Oxygen consumption rates of tilapia in fresh water, sea water, and hypersaline sea water. J Fish Biol 51:886-894

Jung SH, Sim DS, Park MS, Jo Q, Kim Y (2003) Effects of formalin on haematological and blood chemistry in olive flounder, Paralichthys olivaceus (Temminck et Schlegel). Aquac Res 34:1269-1275

Klee M, Eilertson C, Sheridan MA (1990) Nutritional state modulates hormonemediated hepatic glycogenolysis in chinook salmon (Oncorhynchus tshawytscha). J Exp Zool 254:202-206

Klover PJ, Mooney RA (2004) Hepatocytes: critical for glucose homeostasis. Int J Biochem Cell Biol 36:753-758

Kondo H, Kawana Y, Suzuki Y, Hirono I (2014) Comprehensive gene expression profiling in Japanese flounder kidney after injection with two different formalin-killed pathogenic bacteria. Fish Shellfish Immunol 41:437-440

Kullgren A, Samuelsson LM, Larsson DG, Bjornsson BT, Bergman EJ (2010) A metabolomics approach to elucidate effects of food deprivation in juvenile rainbow trout (Oncorhynchus mykiss). Am J Physiol Regul Integr Comp Physiol 299:R1440-R1448

Leonardi MO, Klempau AE (2003) Artificial photoperiod influence on the immune system of juvenile rainbow trout (Oncorhynchus mykiss) in the Southern Hemisphere. Aquaculture 221:581-591

Liu Y, Wang G, Liu Y, Hou J, Wang Y, Si F, Sun Z, Zhang X, Liu H (2012) Genetic verification of doubled haploid Japanese flounder, Paralichthys olivaceus by genotyping telomeric microsatellite loci. Aquaculture 324-325:60-63

Livak KJ, Schmittgen TD (2001) Analysis of relative gene expression data using real-time quantitative PCR and the $2-\triangle \triangle C T$ method. Methods 25:402-408

Lu W, Worthington J, Riccardi D, Balment RJ, McCrohan CR (2007) Seasonal changes in peptide, receptor and ion channel mRNA expression in the caudal neurosecretory system of the European flounder (Platichthys flesus). Gen Comp Endocrinol 153:262-272
Mariano AC, Santos R, Gonzalez MS, Feder D, Machado EA, Pascarelli B, Gondim KC, Meyer-Fernandes JR (2009) Synthesis and mobilization of glycogen and trehalose in adult male Rhodnius prolixus. Arch Insect Biochem Physiol 72:1-15

Moustakas CT, Watanabe WO, Copeland KA (2004) Combined effects of photoperiod and salinity on growth, survival, and osmoregulatory ability of larval southern flounder Paralichthys lethostigma. Aquaculture 229:159-179

Mulder H, Holst LS, Svensson H, Degerman E, Sundler F, Ahrén B, Rorsman P, Holm C (1999) Hormone-sensitive lipase, the rate-limiting enzyme in triglyceride hydrolysis, is expressed and active in beta-cells. Diabetes 48:228-232

Oner M, Atli G, Canli M (2008) Changes in serum biochemical parameters of freshwater fish Oreochromis niloticus following prolonged metal (Ag, Cd, Cr, Cu, Zn) exposures. Environ Toxicol Chem 27:360-366

Park IS, Hur JW, Choi JW (2012) Hematological responses, survival, and respiratory exchange in the Olive flounder, Paralichthys olivaceus, during starvation. Asian Australas J Anim Sci 25:1276-1284

Pavlidis M, Greenwood L, Paalavuo M, Mölsä H, Laitinen JT (1999) The effect of photoperiod on diel rhythms in serum melatonin, cortisol, glucose, and electrolytes in the common dentex, dentex dentex. Gen Comp Endocrinol 113:240-250

Reshef L, Olswang Y, Cassuto H, Blum B, Croniger CM, Kalhan SC, Tilghman SM, Hanson RW (2003) Glyceroneogenesis and the triglyceride/fatty acid cycle. J Biol Chem 278:30413-30416

Sonmez AY, Hisar O, Hisar SA, Alak G, Aras MS, Yanik T (2009) The effects of different photoperiod regimes on growth, feed conversion rate and survival of rainbow trout (Oncorhynchus mykiss) fry. J Anim Vet Adv 8:760-763

Tandler A, Helps S (1985) The effects of photoperiod and water exchange rate on growth and survival of gilthead sea bream (Sparus aurata, Linnaeus; Sparidae) from hatching to metamorphosis in mass rearing systems. Aquaculture 48:71-82

Taylor JF, Migaud H, Porter MJ, Bromage NR (2005) Photoperiod influences growth rate and plasma insulin-like growth factor-I levels in juvenile rainbow trout, Oncorhynchus mykiss. Gen Comp Endocrinol 142:169-185

Tian J, Wen H, Zeng L-B, Jiang M, Wu F, Liu W, Yang C-G (2013) Changes in the activities and mRNA expression levels of lipoprotein lipase (LPL), hormone-sensitive lipase (HSL) and fatty acid synthetase (FAS) of Nile tilapia (Oreochromis niloticus) during fasting and re-feeding. Aquaculture 400-401:29-35

Urbina MA, Glover CN (2015) Effect of salinity on osmoregulation, metabolism and nitrogen excretion in the amphidromous fish, inanga (Galaxias maculatus). J Exp Mar Biol Ecol 473:7-15

Vijayan MM, Reddy PK, Leatherland JF, Moon TW (1994) The effects of cortisol on hepatocyte metabolism in rainbow trout: a study using the steroid analogue RU486. Gen Comp Endocrinol 96:75-84

Vijayan M, Morgan J, Sakamoto T, Grau E, Iwama G (1996) Food-deprivation affects seawater acclimation in tilapia: hormonal and metabolic changes. J Exp Biol 199:2467-2475

Vijayan MM, Raptis S, Sathiyaa R (2003) Cortisol treatment affects glucocorticoid receptor and glucocorticoid-responsive genes in the liver of rainbow trout. Gen Comp Endocrinol 132:256-263

Wells RM, Mclntyre RH, Morgan AK, Davie PS (1986) Physiological stress responses in big gamefish after capture: observations on plasma chemistry and blood factors. Comp Biochem Physiol A Comp Physiol 84:565-571

Xu D, Li S, Lou B, Zhang Y, Zhan W, Shi H (2012) Genetic diversity in two Japanese flounder populations from China seas inferred using microsatellite markers and COI sequences. Chin J Oceanol Limnol 30:604-610 